Article

\title{
Dust and Smoke Detection for Multi-Channel Imagers
}

\author{
Tom X.-P. Zhao ${ }^{1, *}$, Steve Ackerman ${ }^{2}$ and Wei Guo ${ }^{3}$
}

1 National Climatic Data Center, NOAA/NESDIS, Asheville, NC 28801, USA

2 Cooperative Institute for Meteorological Satellite Studies (CIMSS), University of Wisconsin, Madison, WI 53706, USA; E-Mail: steve.ackerman@ssec.wisc.edu

3 I. M. System Group, Inc., 3401 Boxhill Place, Kensington, MD 20895, USA;

E-Mail: Wei.Guo@noaa.gov

* Author to whom correspondence should be addressed; E-Mail: Xuepeng.Zhao@ noaa.gov.

Received: 27 August 2010; in revised form: 28 September 2010 / Accepted: 30 September 2010 / Published: 11 October 2010

\begin{abstract}
A detection algorithm of dust and smoke for application to satellite multi-channel imagers is introduced in this paper. The algorithm is simple and solely based on spectral and spatial threshold tests along with some uniformity texture. Detailed examinations of the threshold tests are performed along with explanations of the physical basis. The detection is performed efficiently at the pixel level and output is in the form of an index (or flag): 0 (no dust/smoke) and 1 (dust/smoke). The detection algorithm is implemented sequentially and designed to run on segments of data instead of pixel by pixel for efficient processing. MODIS observations are used to test the operation and performance of the algorithm. The algorithm can capture heavy dust and smoke plumes very well over both land and ocean and therefore is used as a global detection algorithm. The method can be applied to any multi-channel imagers with channels at (or close to) 0.47, 0.64, 0.86, 1.38, 2.26, 3.9, 11.0, $12.0 \mu \mathrm{m}$ (such as current EOS/MODIS and future JPSS/VIIRS and GOES-R/ABI) for the detection of dust and smoke. It can be used to operationally monitor the outbreak and dispersion of dust storms and smoke plumes that are potentially hazardous to our environment and impact climate.
\end{abstract}

Keywords: dust; smoke; detection algorithm; satellite imagers 


\section{Introduction}

Aerosols perturb the Earth's energy budget by scattering and absorbing radiation and by altering cloud properties and lifetimes. They also exert large influences on weather, air quality, hydrological cycles, and ecosystems. Industrialization and human activities in the past several decades have caused changes to the air quality and Earth's climate by releasing excessive amounts of trace gases and aerosol particles [1]. It is compelling to regularly monitor the global aerosol distributions and study how they are changing, especially for those aerosols with large spatial and temporal variability, such as dust storms and smoke plumes. Detection of these highly variable aerosol events is challenging because of: episodic features, short lifetimes, multiple-scales, and strong impact of local surface and meteorological conditions.

Mineral dust and smoke particles can directly alter solar and Earth radiation in both visible and infrared (IR) spectral regions through scattering and absorption processes. Due to specific optical properties of dust and smoke particles, satellite observed radiances carry the spectral signatures of dust and smoke particles that are different from molecular, cloud, and underlying surface. Based on these differences, various detection schemes have been developed to distinguish dust and smoke (e.g., [2,3-8]. In practice, the detection is based on the analysis of reflectance (or radiance) in visible bands or brightness temperature (BT) in IR bands. The magnitude of the difference in reflectance or BT in selected bands (or channels) can be used to infer the signature of dust and smoke. This is the essence of aerosol imagery detection algorithms. In this paper, we introduce a detection algorithm of dust storms and smoke plumes, respectively, for satellite multi-channel imagers by combing visible channel radiances/reflectances with IR channel brightness temperatures. Dust and smoke detection algorithms are introduced in Section 2 and 3, respectively; Detection results are given in Section 4; Comparison with quantitative aerosol optical thickness (AOT) retrieval is performed in Section 5; and summary and conclusions are given in the closing section.

\section{Dust Detection Algorithm}

Dust detection is performed only for daytime (defined as solar zenith angle $<80$ degrees) in this algorithm. Different detecting schemes are developed for land and ocean and are discussed below. Let's first define some variables and their symbols that will be used throughout the paper:

$\mathrm{BT}$ - brightness temperature (wavelength is given in subscript, e.g., $\mathrm{BT}_{11 \mu \mathrm{m}}$ )

$\mathrm{R}$-reflectance (wavelength is given in subscript, e.g., $\mathrm{R}_{0.64 \mu \mathrm{m}}$ )

BTD-brightness temperature difference

MeanR - mean of reflectance for 3 x 3 pixels (wavelength is given in subscript, e.g., MeanR $R_{0.86 \mu m}$ )

StdR - standard deviation of reflectance for 3 x 3 pixels (wavelength is given in subscript, e.g., $\left.\mathrm{StdR}_{0.86 \mu \mathrm{m}}\right)$

$\mathrm{Rat}_{1}=\left(\mathrm{R}_{0.64 \mu \mathrm{m}}-\mathrm{R}_{0.47 \mu \mathrm{m}}\right) /\left(\mathrm{R}_{0.64 \mu \mathrm{m}}+\mathrm{R}_{0.47 \mu \mathrm{m}}\right)$

$\mathrm{Rat}_{2}=\left(\mathrm{Rat}_{1} \times \mathrm{Rat}_{1}\right) /\left(\mathrm{R}_{0.47 \mu \mathrm{m}} \times \mathrm{R}_{0.47 \mu \mathrm{m}}\right)$

$\mathrm{R}_{1}=\mathrm{R}_{0.47 \mu \mathrm{m}} / \mathrm{R}_{0.64 \mu \mathrm{m}}$

$\mathrm{R}_{2}=\mathrm{R}_{0.86 \mu \mathrm{m}} / \mathrm{R}_{0.64 \mu \mathrm{m}}$

$\mathrm{NDVI}=\left(\mathrm{R}_{0.86 \mu \mathrm{m}}-\mathrm{R}_{0.64 \mu \mathrm{m}}\right) /\left(\mathrm{R}_{0.86 \mu \mathrm{m}}+\mathrm{R}_{0.64 \mu \mathrm{m}}\right)$ 
$\mathrm{MNDVI}=\mathrm{NDVI}^{2} /\left(\mathrm{R}_{0.64 \mu \mathrm{m}} \times \mathrm{R}_{0.64 \mu \mathrm{m}}\right)$.

\subsection{Dust Detection over Land}

Dust detection over land is not performed over snow and ice or in the presence of higher ice clouds due to bright surface perturbation on the aerosol signal. The specific visible reflectance and IR brightness temperature tests currently implemented are:

(1) Good data test for BT and R:

- $\quad \mathrm{R}_{0.47 \mu \mathrm{m}}, \mathrm{R}_{0.64 \mu \mathrm{m}}, \mathrm{R}_{0.86 \mu \mathrm{m}}, \mathrm{R}_{1.38 \mu \mathrm{m}}>0$

- $\quad \mathrm{BT}_{3.9 \mu \mathrm{m}}, \mathrm{BT}_{11 \mu \mathrm{m}}, \mathrm{BT}_{12 \mu \mathrm{m}}>0 \mathrm{~K}$

(2) BTD and R tests:

- $\quad \mathrm{BT}_{11 \mu \mathrm{m}}-\mathrm{BT}_{12 \mu \mathrm{m}} \leq-0.5 \mathrm{~K} \& \mathrm{BT}_{3.9 \mu \mathrm{m}}-\mathrm{BT}_{11 \mu \mathrm{m}} \geq 20 \mathrm{~K} \& \mathrm{R}_{1.38 \mu \mathrm{m}}<0.055$

(screen for pixels that are water cloud free. If these conditions are not met, then the pixels are cloudy and terminate testing)

(3) Dust test:

- $\quad$ If $\mathrm{BT}_{3.9 \mu \mathrm{m}}-\mathrm{BT}_{11 \mu \mathrm{m}} \geq 25 \mathrm{~K}$ then dust

- If MNDVI $<0.08 \& \mathrm{Rat}_{2}>0.005$ then dust

(4) Thick dust test:

- $\quad \mathrm{BT}_{11 \mu \mathrm{m}}-\mathrm{BT}_{12 \mu \mathrm{m}} \leq-0.5 \mathrm{~K} \& \mathrm{BT}_{3.9 \mu \mathrm{m}}-\mathrm{BT}_{11 \mu \mathrm{m}} \geq 25 \mathrm{~K} \& \mathrm{R}_{1.38 \mu \mathrm{m}}<0.035$

- $\quad$ MNDVI $<0.2$

The above conditions (1) and (2) are used to remove bad observations and cloudy pixels, respectively. For condition (3), if $\mathrm{BT}_{3.9 \mu \mathrm{m}}-\mathrm{BT}_{11 \mu \mathrm{m}} \geq 25 \mathrm{~K}$ is satisfied, the pixel is flagged as dust laden. This is because dust reflects solar energy at $3.9 \mu \mathrm{m}$ and so increases the brightness temperature difference with $\mathrm{BT}_{11 \mu \mathrm{m}}$ during the day. Moreover, MNDVI $<0.08$ and $\mathrm{Rat}_{2}>0.005$ are added to identify dust over some semi-arid surfaces with small amounts of vegetation. This is because dust absorbs at blue wavelengths and appears visually to be brownish in color. Clouds are spectrally neutral and appear white to our eyes. For this reason, the reflectances at $0.86,0.64$ and $0.47 \mu \mathrm{m}$ have been used to identify dust. This is often done in a ratio of one to another or as a normalized difference index (such as MNDVI or Rat ${ }_{2}$ ). For example, for a MODIS granule with dust plume over Mexico (see Figure 1), we select the pixels of clear-sky (cl), dust (ds), and cloud (cd) in the regions defined by the three red rectangles and display them in scatter plots of Figure 2. Dust pixels are confined in the range of MNDVI $<0.08$ and $\mathrm{Rat}_{2}>0.005$. In the ratio tests described here, we square the reflectances trying to take better advantage of the non-linear behavior. 
Figure 1. Aqua MODIS RGB image for a granule with dust plume over Mexico. cl, ds, and cd symbols represent clear-sky, dust, and cloud, respectively.

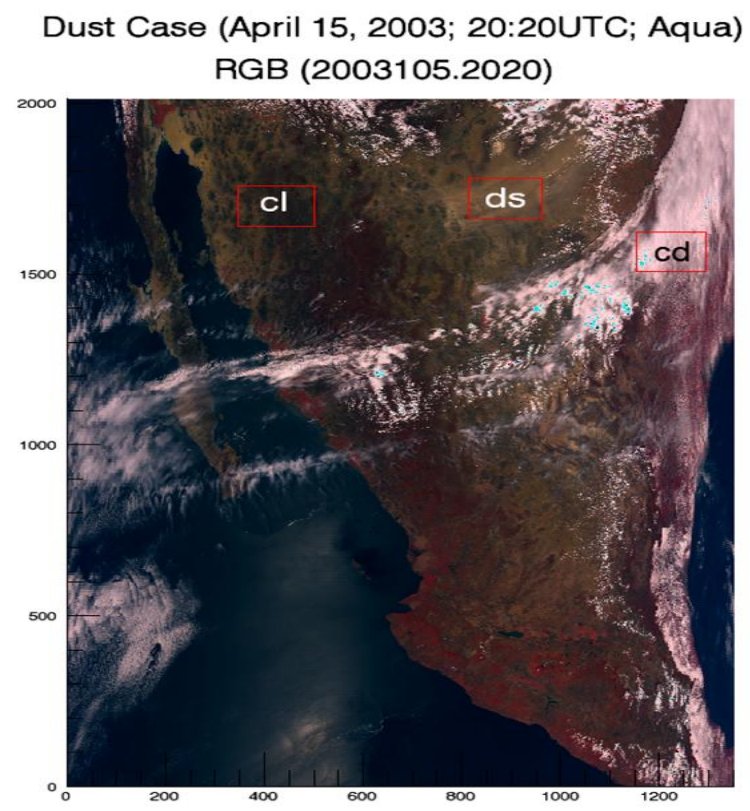

Figure 2. Scatter plot of MNDVI versus Rat $_{2}$ for dust (yellow x's) and cloud (black crosses) pixels in Figure 1.

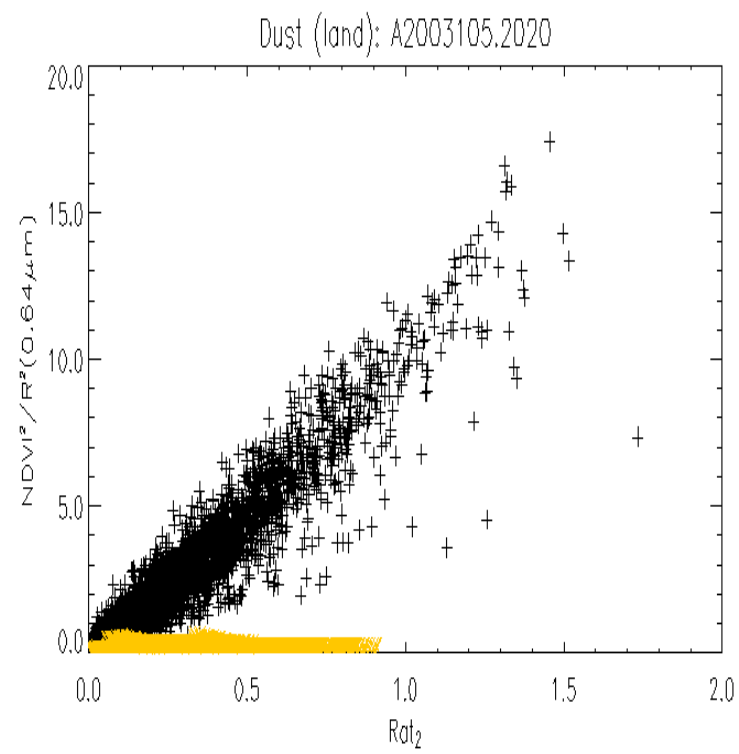

Two tests are used to indicate the presence of optically thick dust in condition (4). The first is $\mathrm{BT}_{11 \mu \mathrm{m}}-\mathrm{BT}_{12 \mu \mathrm{m}} \leq-0.5 \mathrm{~K}$ and $\mathrm{BT}_{3.9 \mu \mathrm{m}}-\mathrm{BT}_{11 \mu \mathrm{m}} \geq 25 \mathrm{~K}$ and $\mathrm{R}_{1.38 \mu \mathrm{m}}<0.035$. The bulk transmittance of many aerosols displays a strong spectral variation in the $8-10 \mu \mathrm{m}$ and $10-12 \mu \mathrm{m}$ regions. This is also a spectral region over which the atmosphere is fairly transparent (or window regions). For these reasons, techniques have been developed which successfully employ satellite radiance measurements at 11 and $12 \mu \mathrm{m}$ to detect aerosols. These split window IR techniques have primarily been applied to the detection of volcanic aerosols, particularly those from sulfur-rich eruptions [e.g., 9,10], and dust 
outbreaks [11-13]. As demonstrated in Figure 3 for the case of Figure 1, dust absorbs more radiation at $12 \mu \mathrm{m}$ than $11 \mu \mathrm{m}$, which causes the brightness temperature difference between the two to become negative. Moreover, there is absorption and emission of water vapor in the 11 and $12 \mu \mathrm{m}$ channels. Because the weighting function for the $11 \mu \mathrm{m}$ channel peaks lower in the atmosphere (higher in temperature) than the $12 \mu \mathrm{m}$ channel does, the presence of a dry air mass, often associated with dust events, will tend to reduce the positive $\mathrm{BT}_{11 \mu \mathrm{m}}-\mathrm{BT}_{12 \mu \mathrm{m}}$ values associated with clear-sky atmospheres. In addition, dust has a larger absorption at $12 \mu \mathrm{m}$ than at $11 \mu \mathrm{m}$, so that dust plumes generally have a higher emissivity and lower transmissivity in the $12 \mu \mathrm{m}$ channel [4,14]. For elevated dust layers, the increased temperature separation between the dust layer and the surface, and the coincident reduction of dry air closer to the peak of the $11 \mu \mathrm{m}$ weighting function, makes the split window brightness temperature difference less positive. This difference has also been observed to be affected by the optical thickness of a given dust plume, so that with thick optical thickness the $\mathrm{BT}_{11 \mu \mathrm{m}}-\mathrm{BT}_{12 \mu \mathrm{m}}$ difference has a negative value.

Figure 3. Scatter plot of the brightness temperature difference between MODIS 3.9 and $11.0 \mu \mathrm{m}$ versus that between MODIS 11.0 and $12.0 \mu \mathrm{m}$ for dust (yellow x's), clear-sky (light-blue crosses), and cloud (black crosses).

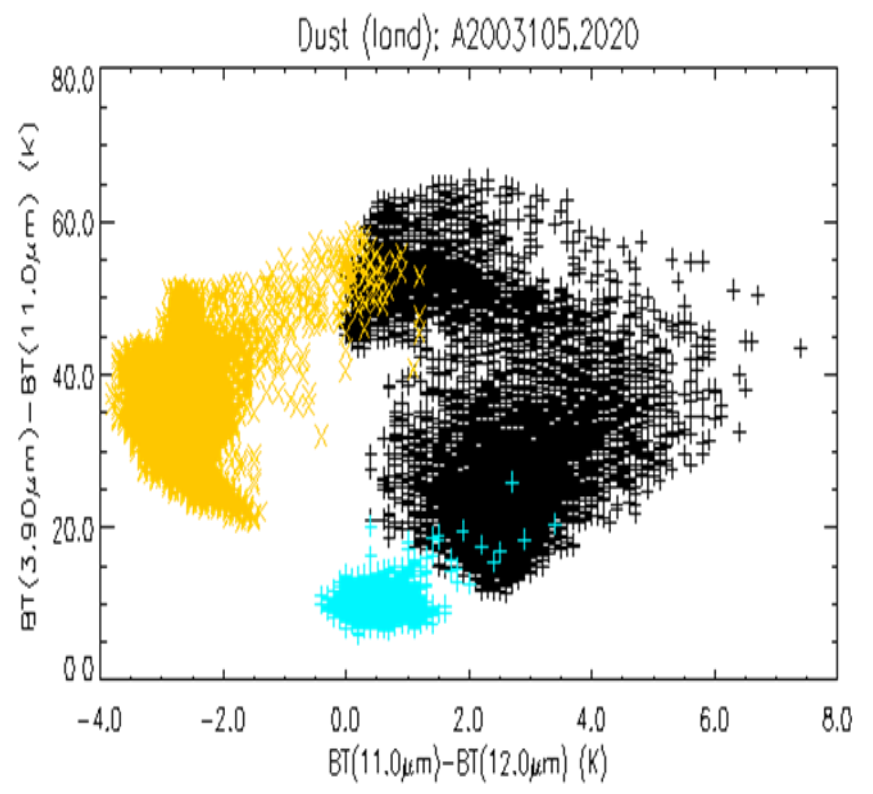

Darmenov and Sokolik [15] further explored the brightness temperature difference technique using MODIS data applied to dust outbreaks from different regions of the globe. In general, $\mathrm{BT}_{8 \mu \mathrm{m}}-\mathrm{BT}_{11 \mu \mathrm{m}}$ becomes less negative and $\mathrm{BT}_{11 \mu \mathrm{m}}-\mathrm{BT}_{12 \mu \mathrm{m}}$ becomes more negative with increasing dust loading, which is confirmed by our analysis as shown in Figure 4 for the case of Figure 1. Since Figure 4 provides similar information content to Figure 3 so that $\mathrm{BT}_{8 \mu \mathrm{m}}-\mathrm{BT}_{11 \mu \mathrm{m}}$ is not used in the current dust detection algorithm. However, low level clouds (often towering cumulus) can also have a negative split window brightness temperature difference. Therefore, two additional tests are applied to attempt screening out cloud contaminated pixels. The first is $\mathrm{BT}_{11 \mu \mathrm{m}}-\mathrm{BT}_{12 \mu \mathrm{m}} \leq-0.5 \mathrm{~K} \& \mathrm{BT}_{3.9 \mu \mathrm{m}}-\mathrm{BT}_{11 \mu \mathrm{m}} \geq 25 \mathrm{~K} \& \mathrm{R}_{1.38 \mu \mathrm{m}}<0.055$ (see Figures 3 and 5). The second test is MNDVI $<0.2$. The MNDVI values for clouds and clear-sky 
are generally larger than 0.2 (as shown in Figure 2 for cloud and the following Figure 5 for clear-sky) but less than this value for dust pixels, especially for heavy dust scenarios.

Figure 4. Scatter plot of the brightness temperature difference between MODIS 8.5 and $11.0 \mu \mathrm{m}$ versus that between MODIS 11.0 and $12.0 \mu \mathrm{m}$ for dust (yellow x's), clear-sky (light-blue crosses), and cloud (black crosses) pixels in Figure 1.

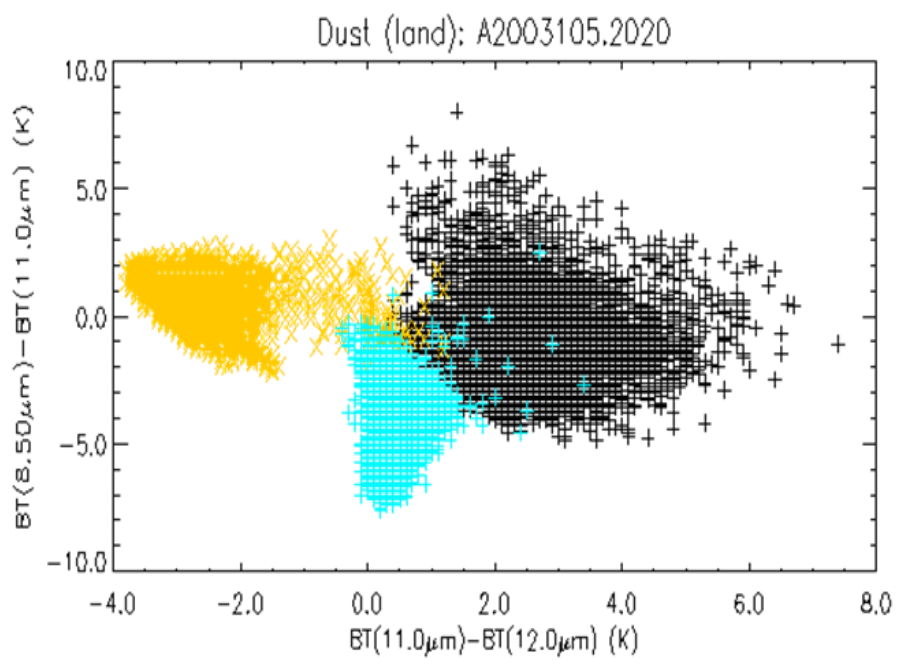

Figure 5. Scatter plot of MNDVI $=\mathrm{NDVI}^{2} /\left(\mathrm{R}_{0.64 \mu \mathrm{m}} \times \mathrm{R}_{0.64 \mu \mathrm{m}}\right)$ versus $\mathrm{R}_{1.38 \mu \mathrm{m}}$ for clear-sky (light-blue crosses) and dust (black crosses).

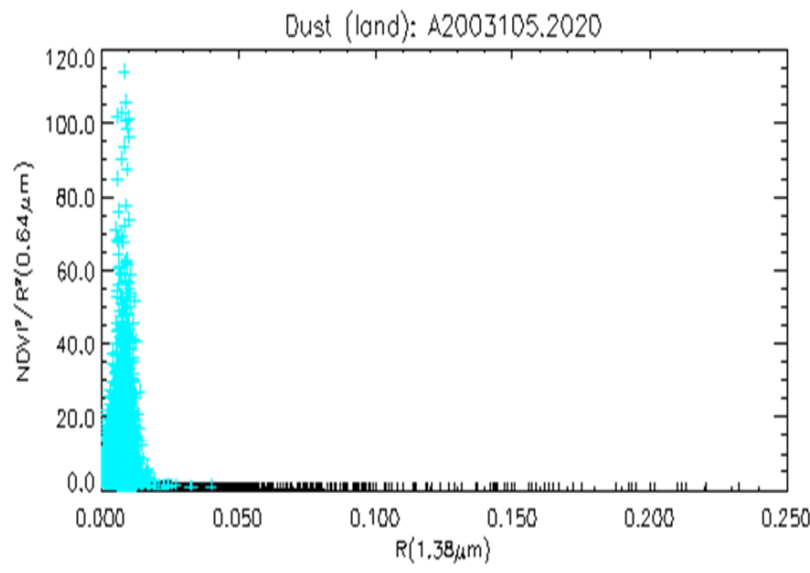

Through the analysis which is similar to Figures $1-5$ for a few of training images over the globe, a set of initial threshold values were selected visually. This selection is somewhat subjective but selected values can reasonably separate dust from clouds and underlying surface for these training cases. These initial thresholds were further refined by application to more sample images mainly through trial-and-error, which is painstaking. The current thresholds need to be further adjusted in future practical operational applications. Similar methodology is also used to determine the threshold values of the smoke detection algorithm introduced below. 


\subsection{Dust Detection over Ocean}

Dust detection over ocean is not performed over sea ice or in the presence of higher ice clouds. The specific tests currently implemented are as follows:

(1) Good data test:

- $\quad \mathrm{R}_{0.47 \mu \mathrm{m}}, \mathrm{R}_{0.64 \mu \mathrm{m}}, \mathrm{R}_{0.86 \mu \mathrm{m}}>0$

- $\quad \mathrm{BT}_{3.9 \mu \mathrm{m}}, \mathrm{BT}_{11 \mu \mathrm{m}}, \mathrm{BT}_{12 \mu \mathrm{m}}>0 \mathrm{~K}$

(2) BTD and R tests plus uniformity texture tests:

- $4 \mathrm{~K}<\mathrm{BT}_{3.9 \mu \mathrm{m}}-\mathrm{BT}_{11 \mu \mathrm{m}} \leq 20 \mathrm{~K}$

- $\quad \mathrm{R}_{0.47 \mu \mathrm{m}} \leq 0.3$

- $\quad$ MeanR $_{0.86 \mu \mathrm{m}}>0$ and $\mathrm{StdR}_{0.86 \mu \mathrm{m}} \leq 0.005(3 \times 3$ pixels $)$ (identify water cloud)

(3) Dust test:

- $\quad$ if $\mathrm{BT}_{11 \mu \mathrm{m}}-\mathrm{BT}_{12 \mu \mathrm{m}}<0.1 \mathrm{~K}$ and $-0.3 \leq \mathrm{NDVI} \leq 0$ then dust

- $\quad$ if $\mathrm{R}_{0.47 \mu \mathrm{m}} / \mathrm{R}_{0.64 \mu \mathrm{m}}<1.2$ then dust

- $\quad$ if $\mathrm{BT}_{3.9 \mu \mathrm{m}}-\mathrm{BT}_{11 \mu \mathrm{m}}>10 \mathrm{~K} \& \mathrm{BT}_{11 \mu \mathrm{m}}-\mathrm{BT}_{12 \mu \mathrm{m}}<-0.1 \mathrm{~K}$ then dust

(4) Thick dust test:

- $\quad \mathrm{BT}_{3.9 \mu \mathrm{m}}-\mathrm{BT}_{11 \mu \mathrm{m}}>20 \mathrm{~K}$ (define potential thick dust regime)

- $\quad$ if $\mathrm{BT}_{11 \mu \mathrm{m}}-\mathrm{BT}_{12 \mu \mathrm{m}} \leq 0 \mathrm{~K}$ and $-0.3 \leq \mathrm{NDVI} \leq 0.05$ then heavy dust

Since dust over ocean is more uniformly distributed than cloud and less reflective than cloud, uniformity test $\left(\operatorname{StdR}_{0.86 \mu \mathrm{m}} \leq 0.005\right)$ and reflectance test $\left(\mathrm{R}_{0.47 \mu \mathrm{m}} \leq 0.3\right)$ are added to BTD test $\left(4 \mathrm{~K}<\mathrm{BT}_{3.9 \mu \mathrm{m}}-\mathrm{BT}_{11 \mu \mathrm{m}} \leq 20 \mathrm{~K}\right)$ to separate better the dust from cloud over ocean. There are three separate tests for dust over water and each is described below. Any pixel that passes any of the three tests is flagged as dusty, although some of the tests have multiple conditions that must be satisfied.

If $\mathrm{BT}_{11 \mu \mathrm{m}}-\mathrm{BT}_{12 \mu \mathrm{m}}<0.1 \mathrm{~K}$ and $-0.3 \leq \mathrm{NDVI} \leq 0$ then the pixel is set as dust contaminated. Ackerman [4] studied the possibility of detecting airborne dust using the difference between the $\mathrm{BT}_{11 \mu \mathrm{m}}$ and $\mathrm{BT}_{12 \mu \mathrm{m}}$. He found that airborne dust caused a depression of this value and therefore may be useful in detecting and tracking dust plumes. This split window brightness temperature difference is also the basis for current efforts to use airborne dust in assisting the tracking of the Saharan air layer [14] using GOES satellite observations. However, the split window difference can also lead to false positive tests, and so it is coupled with a NDVI-type condition of the pixel. The presence of smaller aerosols, like smoke, tends to reduce the values of $R_{0.86 \mu \mathrm{m}} / \mathrm{R}_{0.64 \mu \mathrm{m}}$ ratio, as smaller particles are more efficient at scattering light at $0.64 \mu \mathrm{m}$. Although dust particles are observed to scatter more light at $0.64 \mu \mathrm{m}$ than at $0.86 \mu \mathrm{m}$ probably due to their size, they tend to exhibit more uniform scattering across this spectral region [16]. Thus, the $\mathrm{R}_{0.86 \mu \mathrm{m}} / \mathrm{R}_{0.64 \mu \mathrm{m}}$ ratio test [13] has been found useful in discriminating pixels containing smoke from those with dust. Rather than directly using the ratio, a modified version (or NDVI test) is employed here.

Another test for examining dust over ocean is the requirement of $R_{0.47 \mu \mathrm{m}} / \mathrm{R}_{0.64 \mu \mathrm{m}}<1.2$ since clear-sky ocean surface tends to reflect more in $0.47 \mu \mathrm{m}$ than $0.64 \mu \mathrm{m}$ compared with dust particles. Similar to the dust detection over land, low level clouds (often towering cumulus) can also have a 
negative split window brightness temperature difference. Therefore, the two additional tests $\left(\mathrm{BT}_{3.9 \mu \mathrm{m}}-\mathrm{BT}_{11 \mu \mathrm{m}}>10 \mathrm{~K}\right.$ and $\left.\mathrm{BT}_{11 \mu \mathrm{m}}-\mathrm{BT}_{12 \mu \mathrm{m}}<-0.1 \mathrm{~K}\right)$ are applied to attempt reducing cloud contaminated pixels.

Similar to the tests of heavy dust over land, two conditions that indicate the presence of optically thick dust over ocean are employed. The first test, $\mathrm{BT}_{3.9 \mu \mathrm{m}}-\mathrm{BT}_{11 \mu \mathrm{m}}>20 \mathrm{~K}$, is used to define thick dust regime by separating from thin dust. The second test is $\mathrm{BT}_{11 \mu \mathrm{m}}-\mathrm{BT}_{12 \mu \mathrm{m}} \leq 0 \mathrm{~K}$ and $-0.3 \leq \mathrm{NDVI} \leq 0.05$. The first part of the test associated with BTD is the ocean version of the split window IR detection technique for heavy dust. The second part of the test associated with NDVI is similar to the detection of non-thick dust, which is used to reduce the false detection in the split window test.

The above tests and thresholds have been examined by using MODIS observations. Figure 6 is an example of MODIS granule with dust over the coastal ocean of Africa. Similar to the case of Figure 1 over land, we select pixels with clear-sky (cl), dust (ds), and cloud (cd), in the regions defined by the three red rectangles. and display them in scatter plots in Figure 7. It is seen that dust, cloud, and clear-sky pixels are clustered in different regimes defined by BTDs or reflectances (and/or their ratios). The threshold values set in the detection scheme are well justified. This result is not a surprise since the threshold values are determined by using the similar analysis approach shown in Figure 7 for many sample images.

Figure 6. Terra MODIS RGB image for a granule with dust plume over coastal ocean of Africa. cl, ds, cd symbols represent clear-sky, dust, and cloud, respectively.

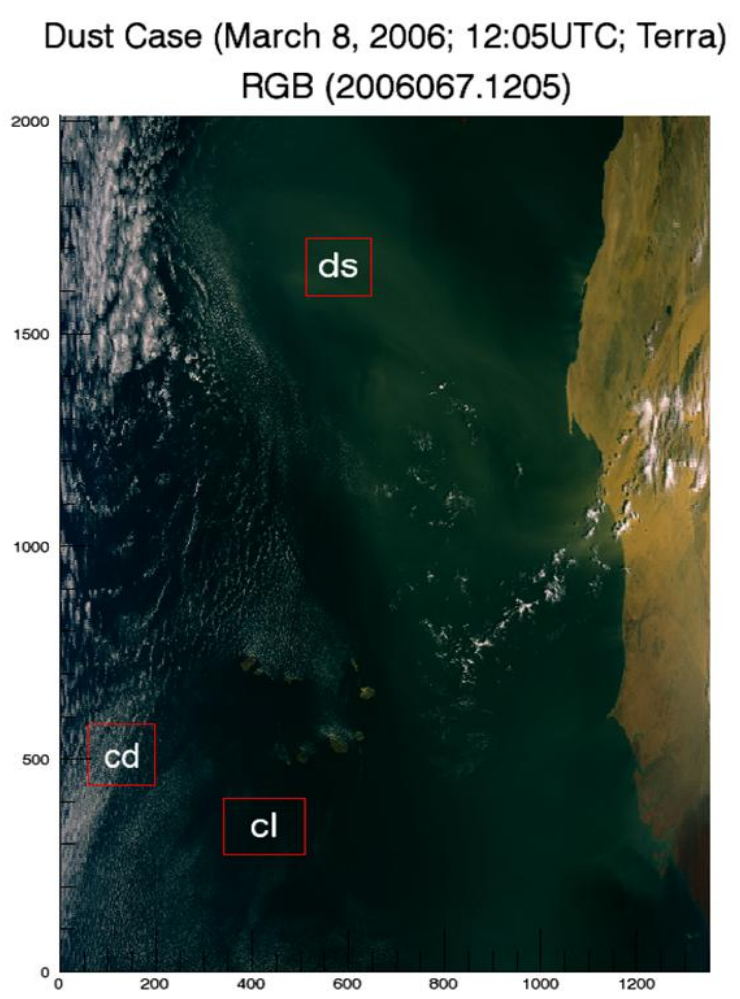


Figure 7. Scatter plots of the BTD and reflectances (and their ratios) in selected MODIS channels for the pixels with dust, clear-sky, and cloud over ocean for the case of Figure 6.

a)

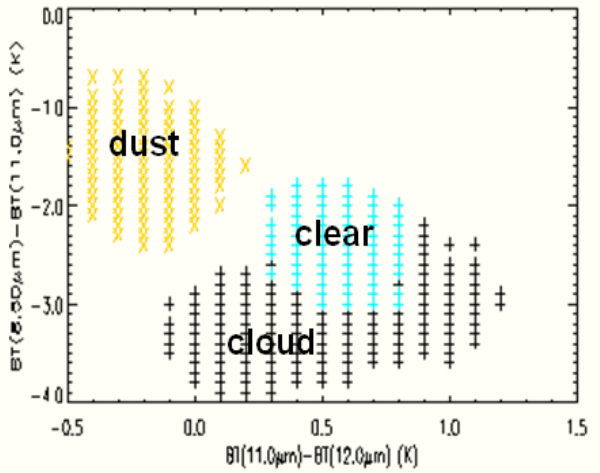

b)

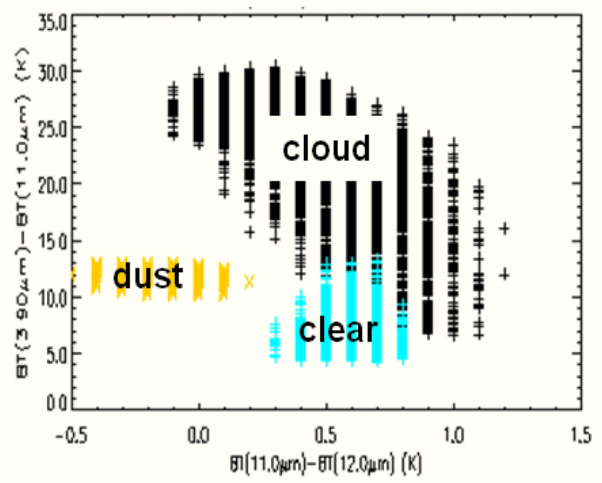

c)

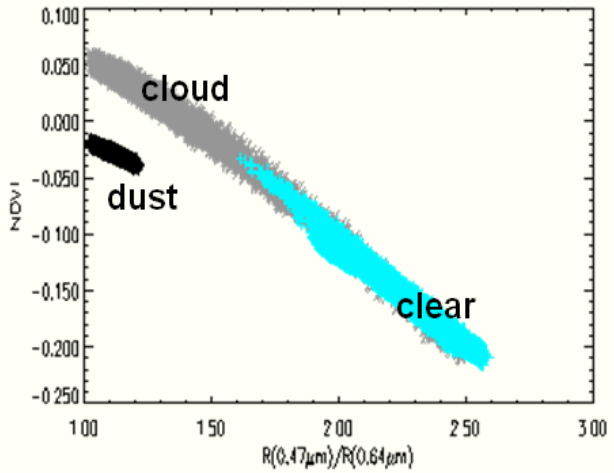

d)

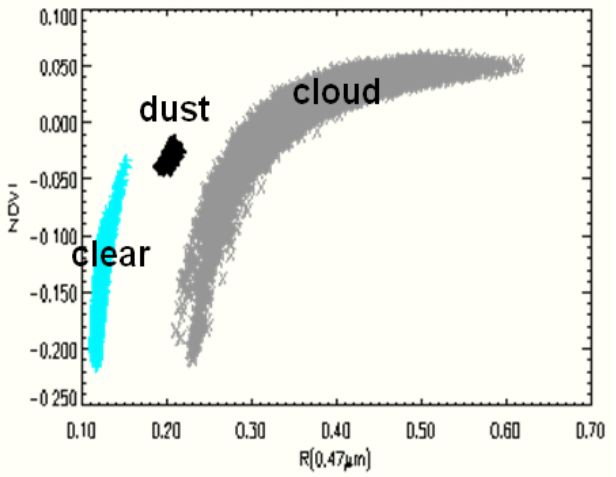

\section{Smoke Detection Algorithm}

Smoke detection is also performed only for daytime. Different detecting schemes are developed for land and ocean and they are introduced below.

\subsection{Smoke Detection over Land}

Smoke detection over land is performed without the presence of higher ice clouds. The specific tests currently implemented are as below:

(1) Good data test:

- $\quad \mathrm{R}_{0.47 \mu \mathrm{m}}, \mathrm{R}_{0.64 \mu \mathrm{m}}, \mathrm{R}_{0.86 \mu \mathrm{m}}, \mathrm{R}_{2.26 \mu \mathrm{m}}>0$

- $\quad \mathrm{BT}_{3.9 \mu \mathrm{m}}, \mathrm{BT}_{11 \mu \mathrm{m}}>0 \mathrm{~K}$

(2) Fire detection:

- $\quad \mathrm{BT}_{3.9 \mu \mathrm{m}}>350 \mathrm{~K}$ and $\mathrm{BT}_{3.9 \mu \mathrm{m}}-\mathrm{BT}_{11 \mu \mathrm{m}} \geq 10 \mathrm{~K}$

(3) Spectral and uniformity tests:

- $\quad \mathrm{R}_{2.26 \mu \mathrm{m}}<0.2$

- $\quad \mathrm{R}_{0.64 \mu \mathrm{m}}>\left(-0.006+0.611 \mathrm{R}_{2.26 \mu \mathrm{m}}\right)$

- $\quad \mathrm{R}_{1} \geq 0.85$ and $\mathrm{R}_{2} \geq 1.0$

- $\quad$ if $\operatorname{StdR}_{0.64 \mu \mathrm{m}} \leq 0.04$ ( $3 \times 3$ pixels) then thick smoke

(4) If fire or thick smoke then smoke. 
First, fires are hot spots with a high brightness temperature at $3.9 \mu \mathrm{m}$. The hot spots are detected with $\mathrm{BT}_{3.9 \mu \mathrm{m}}>350 \mathrm{~K}$ and $\mathrm{BT}_{3.9 \mu \mathrm{m}}-\mathrm{BT}_{11 \mu \mathrm{m}} \geq 10 \mathrm{~K}$ and flagged as fire pixels, with which smoke should be accompanied. The solar channel tests over land take advantage of a linear relationship observed with MODIS for clear sky vegetated land surfaces at $R_{0.64 \mu \mathrm{m}}$ versus $\mathrm{R}_{2.26 \mu \mathrm{m}}$ for $\mathrm{R}_{2.26 \mu \mathrm{m}}<0.2$ (see [5]). The relationship gets noisy once $R_{2.26 \mu m}>0.2$. When smoke is added to the scene, there is a larger increase in $\mathrm{R}_{0.64 \mu \mathrm{m}}$ than $\mathrm{R}_{2.26 \mu \mathrm{m}}$, so smoke contaminated pixels should lie above the linear relationship between the two channels. The value of 0.006 in the test is to avoid the natural variability in surface reflectance. Thus, the initial smoke detection condition of $\mathrm{R}_{2.26 \mu \mathrm{m}}<0.2$ is to identify dark surface, where fire and smoke may break out. $R_{0.64 \mu \mathrm{m}}>\left(-0.006+0.611 \mathrm{R}_{2.26 \mu \mathrm{m}}\right)$ is used to separate from clear-sky surface. In addition, $R_{1} \geq 0.85$ and $R_{2} \geq 1.0$ are used to confine the smoke regime. This definition is not sufficient to completely separate smoke from cloud as illustrated in Figure 8 for a scene with smoke over Georgia shown in Figure 9. Thus, a uniformity test, $\operatorname{StdR}_{0.64 \mu \mathrm{m}} \leq 0.04$, is added to separate heavy smoke from cloud since the reflectance at $0.64 \mu \mathrm{m}$ from clouds in general has a relatively larger spatial variability than that from heavy smoke plume. As a result, the current detection algorithm works better for heavy smoke plume over dark vegetated surface. More research is needed for improving the detection of non-heavy or dispersed smoke, especially over semi-arid land surface. The artificial neural networks (NN) approach [8] is worth further exploration since it has an advantage of producing continuous outputs representing the mixture portions of smoke, cloud, and clear background. However, its limitation of being time consuming for global and operational applications needs to be evaluated carefully.

Figure 8. Scatter plots of $\mathrm{R}_{2}=\mathrm{R}_{0.86 \mu \mathrm{m}} / \mathrm{R}_{0.64 \mu \mathrm{m}}$ versus $\mathrm{R}_{1}=\mathrm{R}_{0.47 \mu \mathrm{m}} / \mathrm{R}_{0.64 \mu \mathrm{m}}$ for clear-sky pixels (blue), smoke pixels (dark), heavy smoke pixels (yellow), and cloudy pixels (gray).

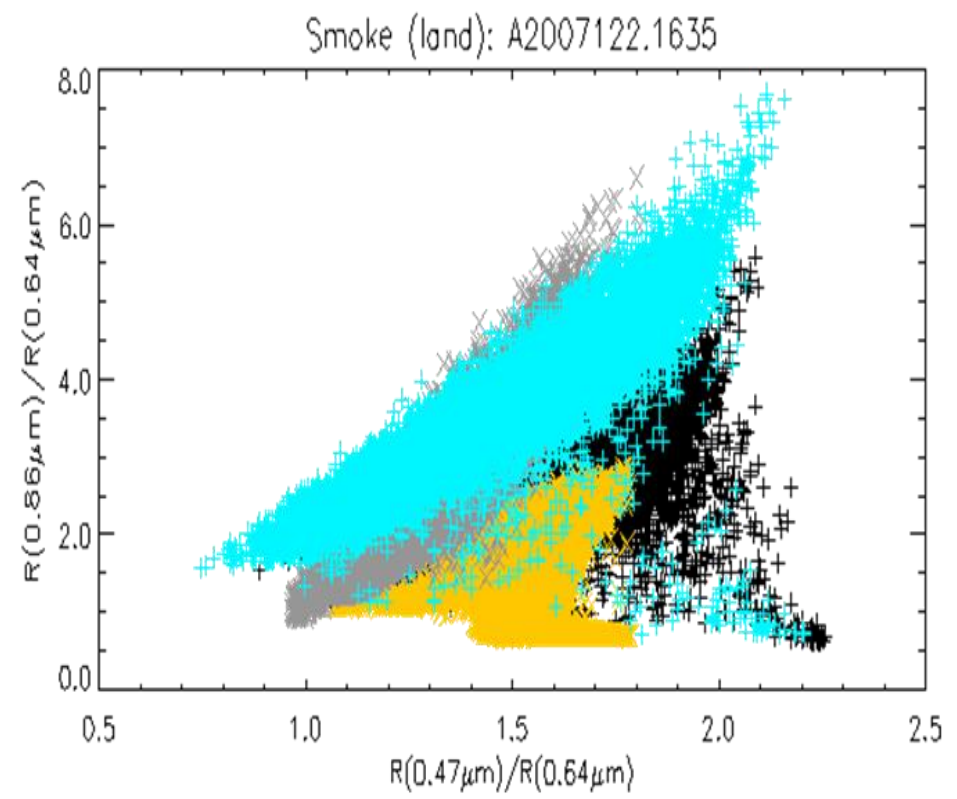


Figure 9. Terra MODIS RGB image for a granule with smoke plume over Georgia. Four rectangle regions influenced, respectively, by cloud (cd), clear-sky (cl), smoke (smoke), and heavy-smoke (hsm) are selected for sensitivity tests.

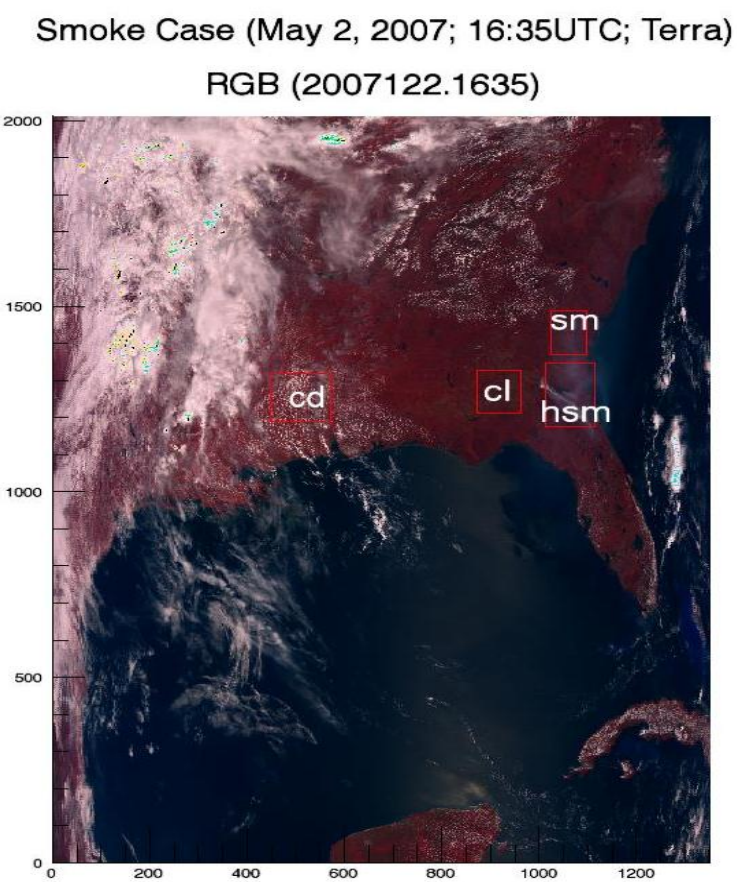

\subsection{Smoke Detection over Ocean}

Smoke detection over ocean is performed without the presence of higher ice clouds. The specific tests currently implemented are as below:

(1) Good data test:

- $\quad \mathrm{R}_{0.47 \mu \mathrm{m}}, \mathrm{R}_{0.64 \mu \mathrm{m}}, \mathrm{R}_{0.86 \mu \mathrm{m}}>0$

- $\quad \mathrm{BT}_{11 \mu \mathrm{m}}>0 \mathrm{~K}$

(2) Reflectance test:

- $\quad 0.2<\mathrm{R}_{0.47 \mu \mathrm{m}}<0.25$ and $0.05<\mathrm{R}_{0.86 \mu \mathrm{m}}<0.15$

(3) Brightness temperature and uniformity test:

- $\quad$ BT $_{11 \mu \mathrm{m}}>290 \mathrm{~K}$

- $\quad \operatorname{StdR}_{0.86 \mu \mathrm{m}} \leq 0.005(3 \times 3$ pixels $)$

(4) Reflectance ratio test:

- $\quad 1.5<\mathrm{R}_{1}<2.0$ and $0.6<\mathrm{R}_{2}<1.0$

Smoke in visible channels looks brighter than ocean surface but darker than cloud. Thus, reflectance from smoke should be larger than that from clear-sky ocean surface but less than that from cloud. To select the proper threshold values for the tests, we examined many MODIS observations with smoke over ocean. As an example, Figure 10 is a MODIS granule with smoke over ocean and its examination is shown in Figure 11. According to the scatter plot of Figure 11 for clear-sky (cl), smoke (sm), and cloud pixels (cd) selected, respectively, from the regions confined by three red rectangles in Figure 10, smoke is confined in the range of $0.2<\mathrm{R}_{0.47 \mu \mathrm{m}}<0.25$ and $0.05<\mathrm{R}_{0.86 \mu \mathrm{m}}<0.15$. Smoke plumes are 
more spatially uniform than clouds and the BT is also warmer than clouds, which is the physical basis of the brightness temperature and spatial uniformity tests. Since smoke and cloud are very similar over ocean, it is very difficult to completely separate them by solely using the reflectance test as seen in Figure 11. However, more information can be used to enhance the separation of cloud and smoke. For example, cloud reflects more at $0.86 \mu \mathrm{m}$ relative to at $0.64 \mu \mathrm{m}$ compared to smoke and both cloud and smoke reflect less at $0.47 \mu \mathrm{m}$ relative to at $0.64 \mu \mathrm{m}$ compared to ocean surface under clear-sky condition. Thus, spectral different reflectance features between smoke and cloud (or smoke and ocean surface) can be further used to separate them. As shown in Figure 12, the reflectance ratio test of $1.5<\mathrm{R}_{1}<2.0$ and $0.6<\mathrm{R}_{2}<1.0$ can help us better separate smoke from cloud and clear-sky over oceans in addition to the reflectance test itself. Thus, our detection scheme includes reflectance test as well as reflectance ratio test.

Figure 10. Terra MODIS RGB image for a granule with smoke plume over ocean. Three rectangle regions influenced, respectively, by cloud (cd), clear-sky (cl), and smoke (smoke) are selected for sensitivity tests.

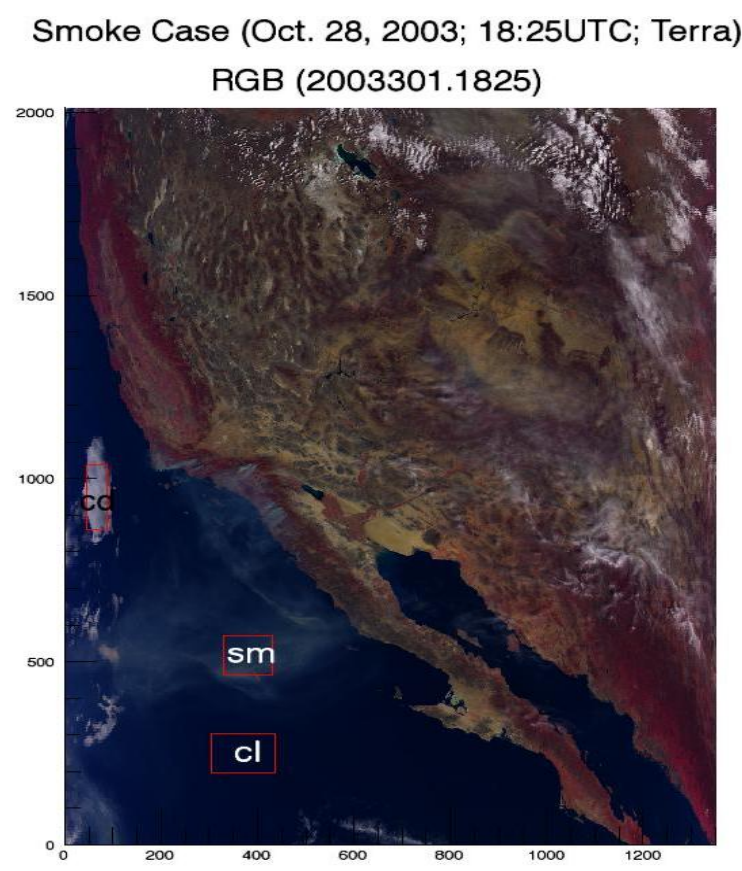

As a summary, the processing outline of our dust and smoke detections is shown in Figure 13, which includes the basic modules for input, output, and detection over land and water. Calibrated/navigated satellite reflectances and brightness temperatures on selected channels, geolocation (latitude/longitude) information, and sensor quality flags are used as the sensor input data for the algorithm. Some ancillary information, including cloud mask, snow/ice mask, sun glint mask, and day/night flag, are needed as input. The final output of the detection algorithm for smoke and dust is a single yes/no mask (or index). The output also includes some cloud screening results, sun glint, surface types for the purpose of QA/QC analysis. The detection algorithm is implemented sequentially. The detection includes checking the validity of each channel before applying the appropriate tests. The detection also expects the Level $1 \mathrm{~b}$ processing to flag any pixels with missing geolocation or viewing 
geometry information. The detection does check for conditions where the algorithm cannot be performed. These conditions include saturated channels. In these non-detection cases, the appropriate flag is set to indicate that no dust or smoke mask was produced for that pixel. To balance the efficiency and memory requirement for the full disk processing from a geostationary satellite, a block of scanning lines are read into a RAM buffer together instead of reading data pixel by pixel. The algorithm is written in $\mathrm{C}++$, and products are output in HDF format.

Figure 11. Scatter plots of $\mathrm{R}_{0.86 \mu \mathrm{m}}$ versus $\mathrm{R}_{0.47 \mu \mathrm{m}}$ for clear-sky pixels (blue), smoke pixels (yellow), and cloudy pixels (black) for the case of Figure 10.

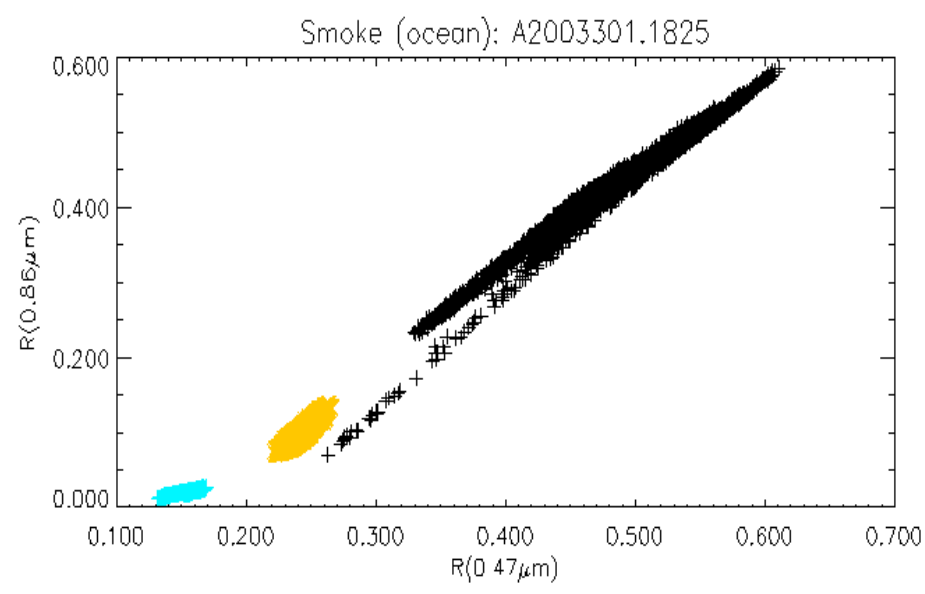

Figure 12. Scatter plot of $R_{2}=R_{0.86 \mu \mathrm{m}} / R_{0.64 \mu \mathrm{m}}$ versus $\mathrm{R}_{1}=\mathrm{R}_{0.47 \mu \mathrm{m}} / \mathrm{R}_{0.64 \mu \mathrm{m}}$ for clear-sky pixels (blue), smoke pixels (yellow), and cloudy pixels (black) for the case of Figure 10.

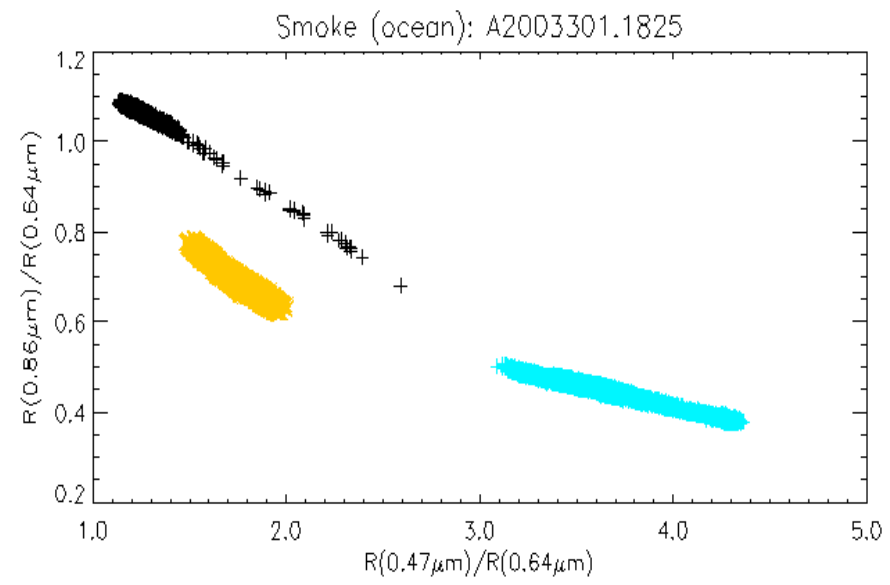


Figure 13. High level flowchart of the dust and smoke detection algorithms, illustrating the main processing sections.

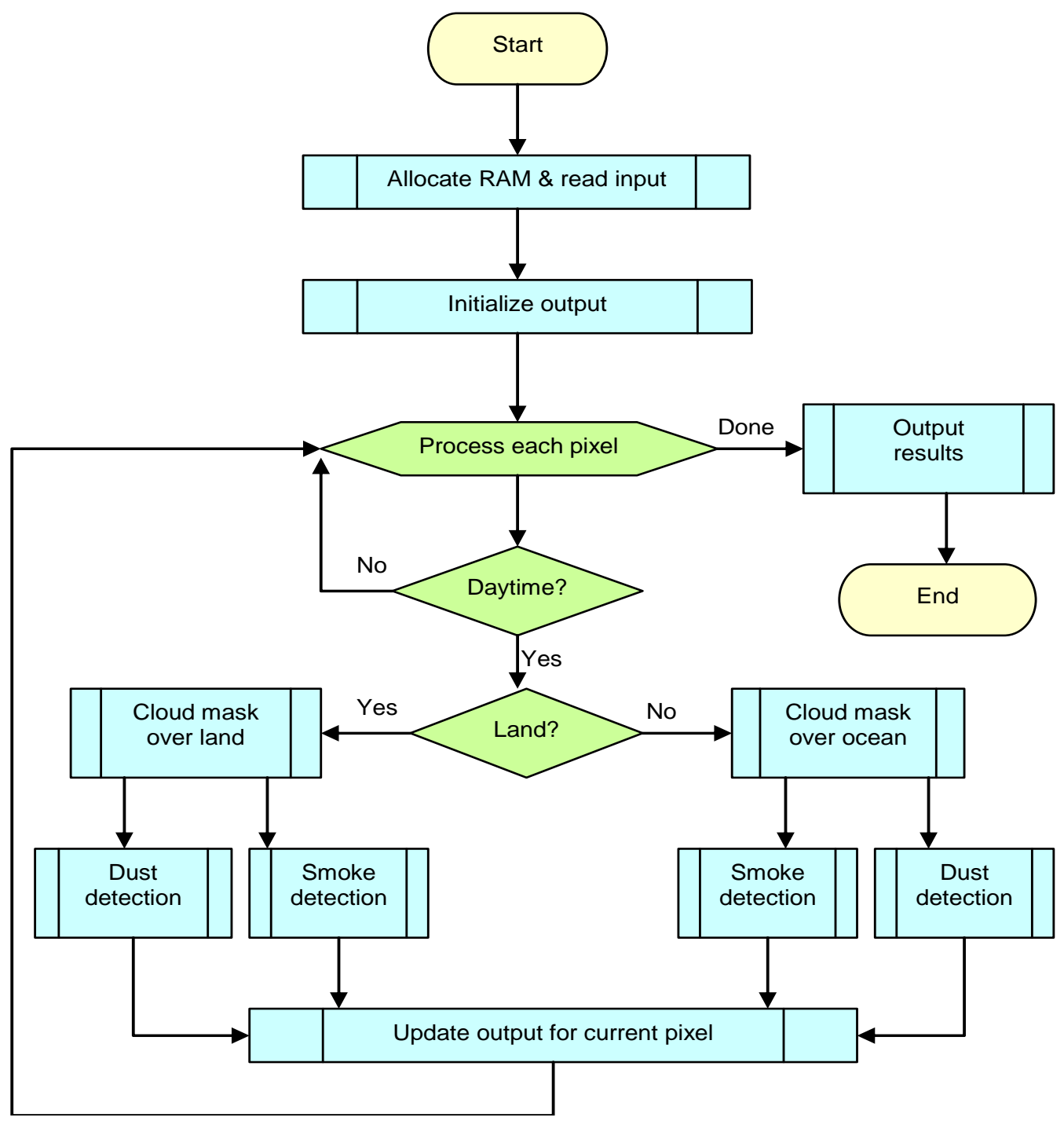

\section{Detection Results and Validation}

The detection algorithm has been tested using measurements from MODIS [17]. Results will be presented below to demonstrate the performance of the algorithm.

\subsection{Dust over Land}

An example of detection results for dust storms over Saudi Arabia desert and Chinese Taklimakan desert is shown in Figure 14. The dust plumes in the red-green-blue (RGB) false color images for both cases (top panels) are captured by the detection algorithm (dust index) very well (bottom panels). A second example is shown in Figure 15, which indicates the dust detection algorithm can even successfully capture small dust outbreak in Mexico. 
Figure 14. Top: red-green-blue (RGB) false color images of an Aqua MODIS observation of dust storm in Saudi Arabia (left) and in Taklimakan desert (right). Bottom: the results of the dust detection where pixels flagged as dusty are red.
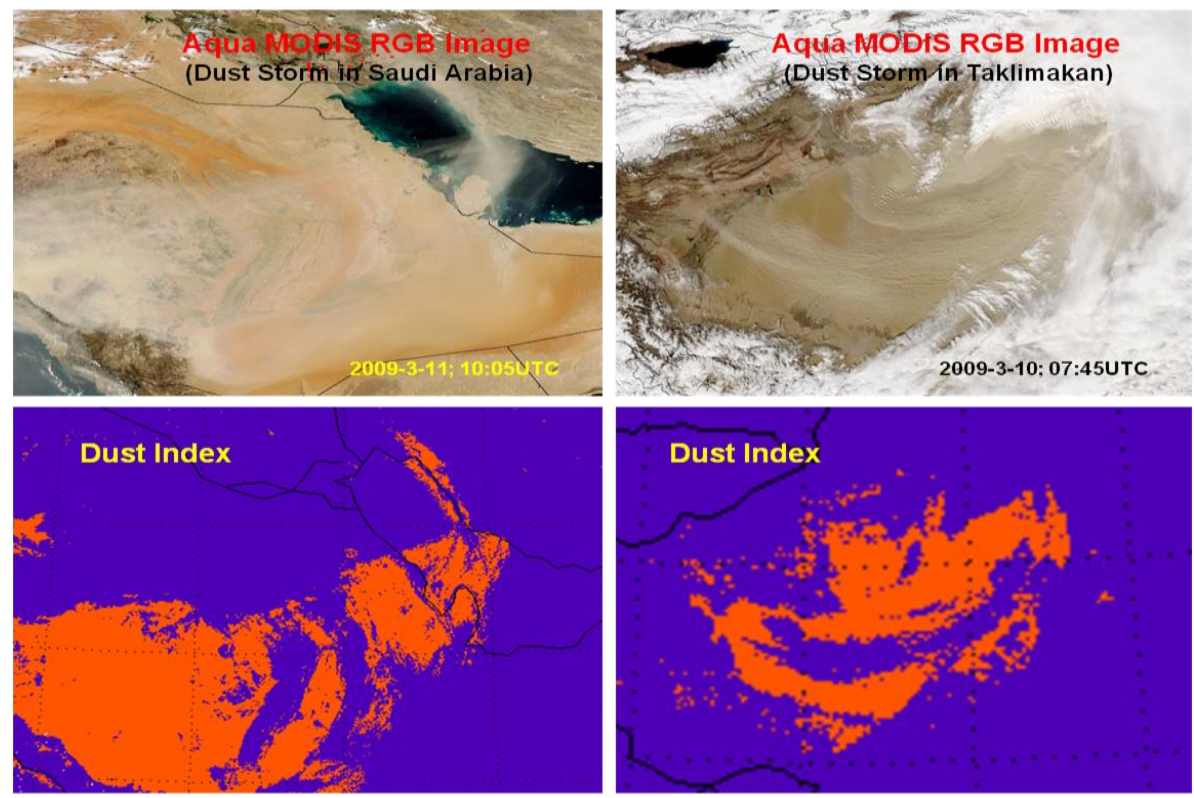

Figure 15. Top: Red-green-blue (RGB) false color images of Aqua MODIS observations. Bottom: The results of the dust test where pixels flagged as dusty are red.

\section{Dust Storm in Mexico}

$(04 / 15 / 2003 ; 20: 20 U T C)$
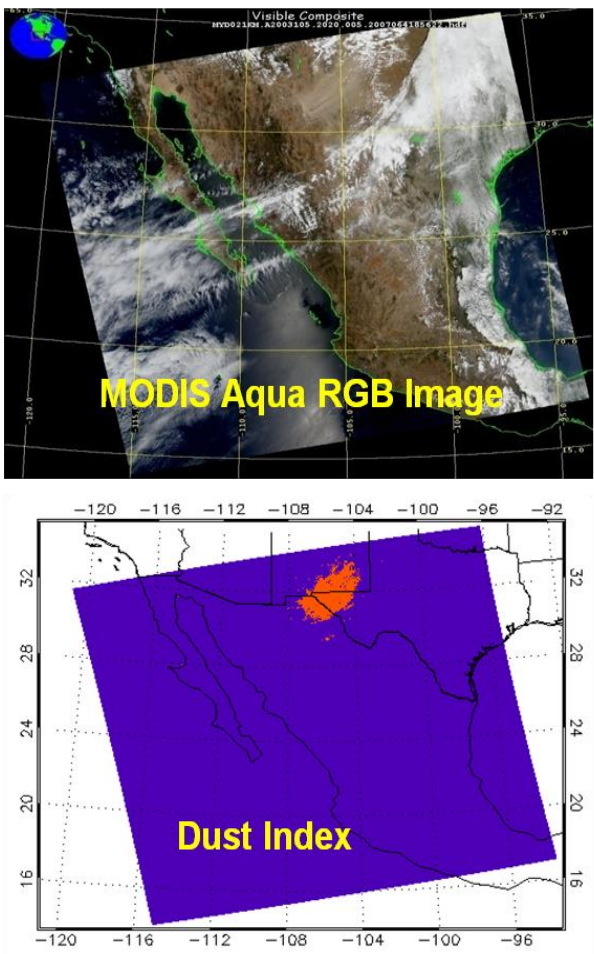

$(03 / 04 / 2004 ; 19: 55 U T C)$
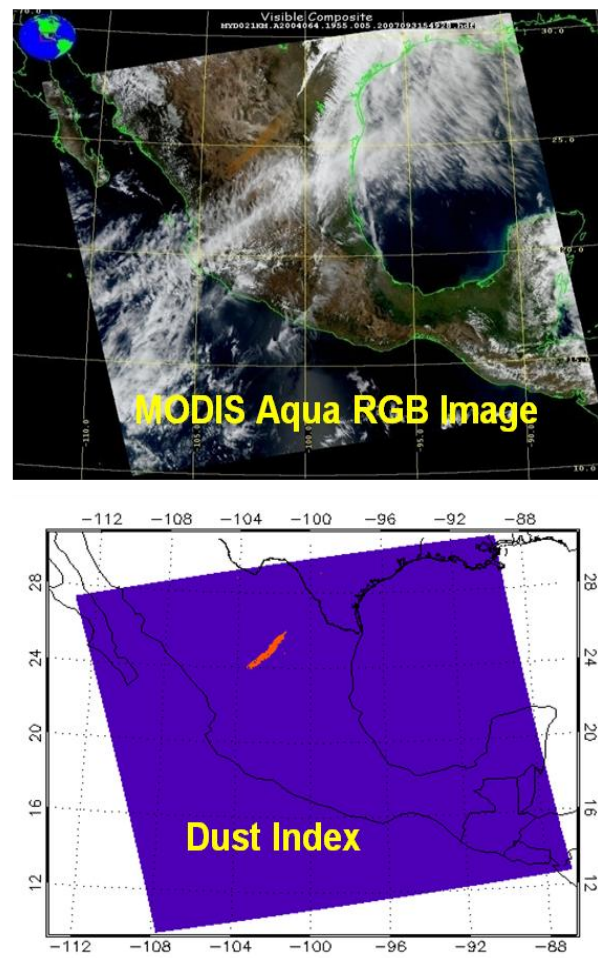


\subsection{Dust over Ocean}

The results of the application of the ocean dust detection to MODIS data on March 8, 2006 at approximate 12:05 UTC is shown in Figure 16. A dust outbreak is flowing from the Sahara desert over the adjacent Atlantic Ocean. The left panel is the RGB image and dust is in brownish color. The dust detection results over water and land are given in right panel, where red regions indicate the presence of dust. Another case is given in Figure 17. The Trans-Atlantic dust (the brownish color in the RGB image) above broken clouds is captured successfully by our detection algorithm.

Figure 16. Terra MODIS RGB Image on March 8, 2006 at about 12:05 UTC in left panel and the results of the dust detection in right panel (pixels flagged as dusty are in red).

Terra MODIS RGB Image

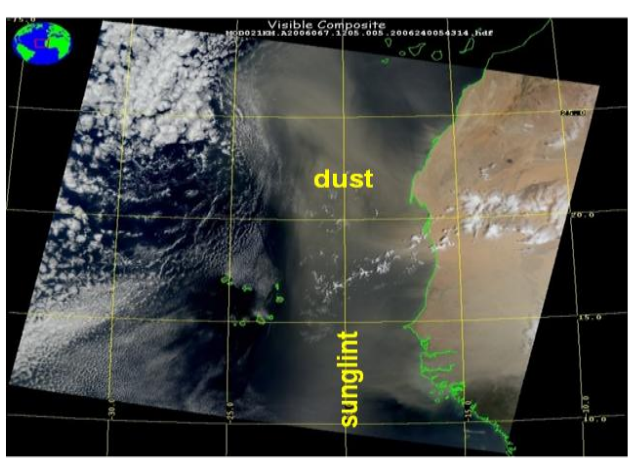

Dust Index

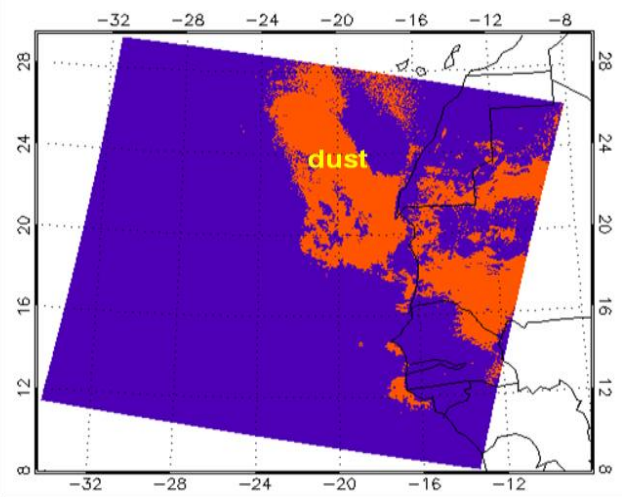

Figure 17. A Sahara dust outbreak is flowing across the Atlantic Ocean above cloud in a RGB image (yellowish color) of left panel and the corresponding dust index (red) of right panel. This is an Aqua MODIS granule on June 23, 2007 at 16:00 UTC.

Aqua MODIS RGB Image

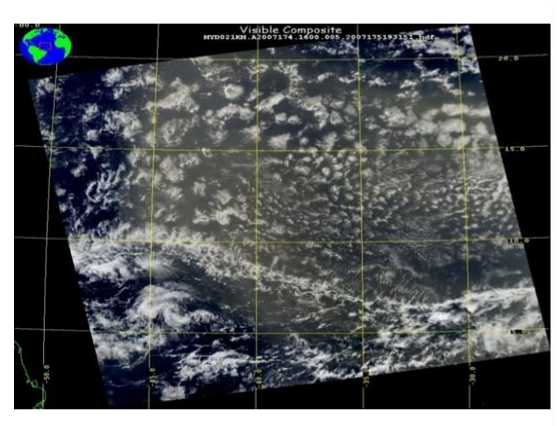

Dust Index

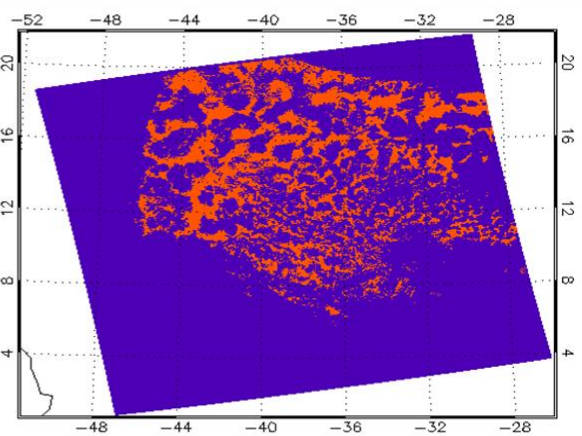

\subsection{Smoke over Land}

The results of the application of the land smoke detection to Aqua MODIS data on August 19, 2003 at approximately 19:00 UTC is shown in Figure 18. Smoke over Ontario and Quebec in Canada are detected. The heavy smoke plumes have been well captured but light plumes were missed. This suggests that the current algorithm still has difficulty separating light smoke plumes from surface, especially for arid and semi-arid surfaces, which deserves further studies for improvement. 
Figure 18. A RGB image of an Aqua MODIS granule on August 19, 2003 at 19:00 UTC is given in the left panel. The results of the smoke detection are shown in the right panel where pixels flagged as smoky are red.
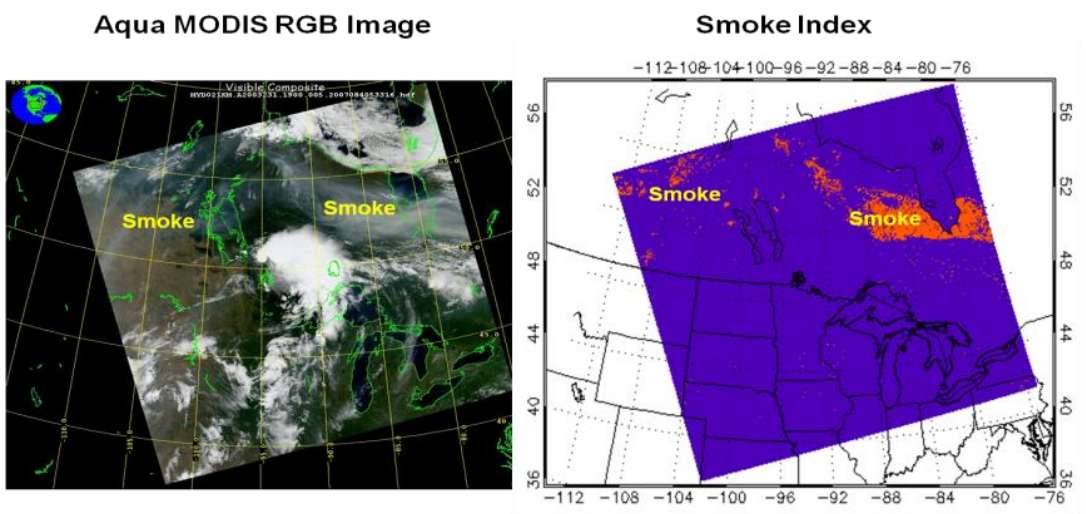

\subsection{Smoke over Ocean}

The results of the application of the ocean smoke detection to Terra MODIS data on October 28, 2003 at approximately 18:25 UTC are shown in Figure 19. Smoke over the coast of California due to dry season fire is detected. The detected coverage of the smoke is somewhat less than that observed from the RGB image. This is because it is still difficult to separate smoke and cloud without any ambiguity over ocean. We prefer to set threshold values for smoke more conservatively to make sure the pixels flagged as smoky are free from cloud contamination, which, on the other hand, may also result in missing thinner smoke plumes in the detection.

Figure 19. A RGB false color image of a Terra MODIS granule on October 28, 2003 at approximately 18:25 UTC in the left panel (cd, cl, and sm represent cloud, clear-sky, and smoke, respectively). The results of the smoke detection are in the right panel where pixels flagged as smoky are red.
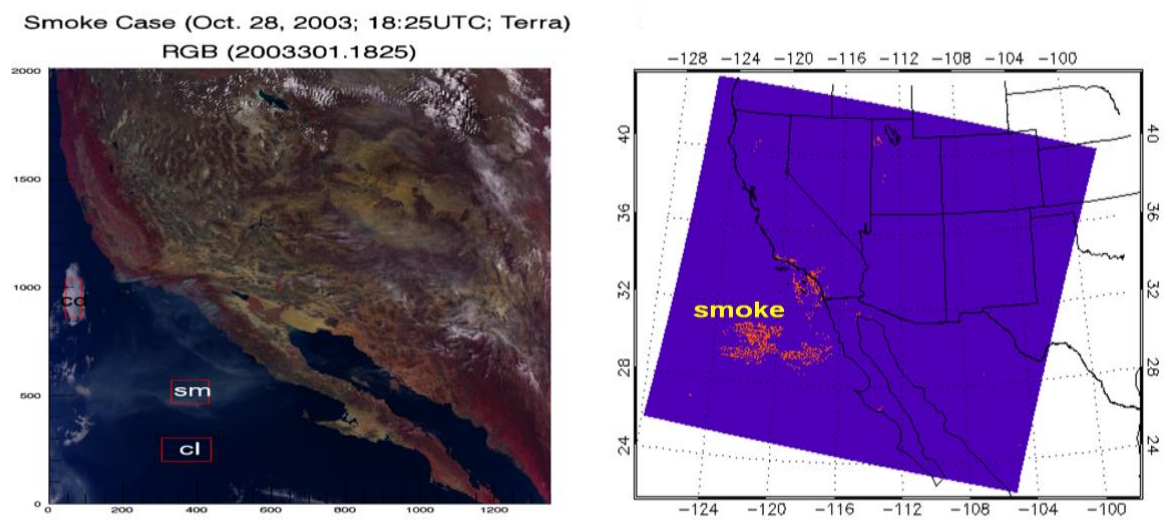

\section{Comparison with MODIS Aerosol Retrieval}

Aside from the comparison of the detection results from MODIS observation with the corresponding MODIS RGB images presented in the previous section, the results are also compared with the aerosol optical thicknesses (AOT) retrieved from the MODIS radiances using a physically 
based algorithm by the official MODIS aerosol team (see [18]) for a further check on the performance of our detection.

Dust particles are mainly located in desert regions and downwind areas, and a dust event is mainly associated with high aerosol optical thickness, so that the AOT distribution retrieved from satellite observation can help us examine the dust detection algorithm based on satellite images. One example is shown in Figure 20 for the same case as Figure 16. Comparison of dust detection flag with MODIS retrieved AOT image shows good consistency, even though MODIS AOT product has gaps in the bright areas (e.g., sun glint region over ocean and desert over land) and very high AOTs are masked as clouds in the MODIS AOT retrieval algorithm. More detailed checks (with the help of the RGB image in Figure 16) indicate that the dust detection algorithm misses some very thin dust plumes but can capture thick dust plumes even in the bright areas, where AOT retrieval is not available. Aside from MODIS AOT product, MODIS aerosol fine mode fraction (FMF) product can also be used to confirm the pixels with high AOT values are with large particles (low FMF values), such as dust. One example comparing RGB image, AOT, and FMF with our dust detection (dust index), is given in Figure 21 for the Trans-Atlantic dust case of Figure 17. Our dust index image compares very well with the corresponding RGB, AOT, and AFM images (remember there is no AOT and AFM retrieval in sun glint region).

In general, aerosol optical thickness of smoke is high and its spatial distribution is in the plume structure. Thus, AOT images can be used to validate our smoke detection result. Figure 22 is an example for the smoke case presented in Figure 18. High AOT plumes compare well with the smoke flags, especially the thicker plumes. As the previous comparison with the RGB image in Figure 18, this comparison with AOT also indicates the current smoke detection scheme has difficulty to capture thinner smoke plumes. Since smoke particles fall in fine mode category, aerosol fine mode fraction (FMF) product produced by MODIS aerosol retrieval can be used together with AOT for the validation of smoke detection to identify the existence of smaller smoke particles (with high FMF value) as for the validation of dust detection.

Figure 20. Comparison of MODIS AOT retrieval (left panel) with the dust detection result (right panel) for the case of Figure 16. There is no MODIS AOT retrieval for bright areas (e.g., sun glint region over ocean and desert over land).

MODIS AOT

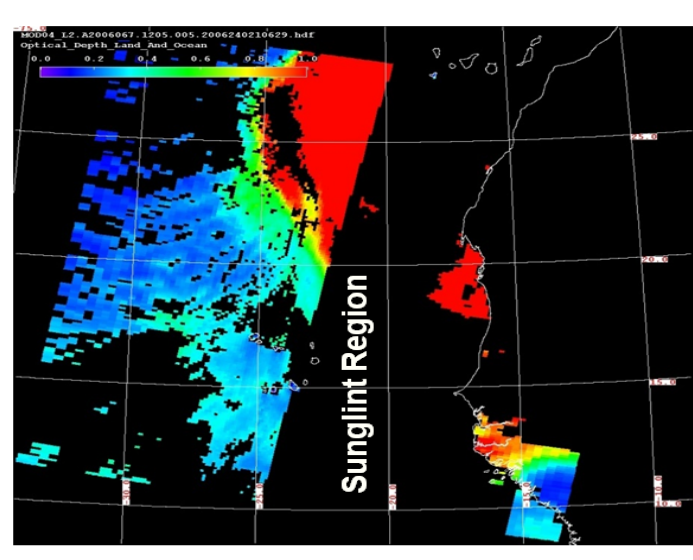

Dust Index

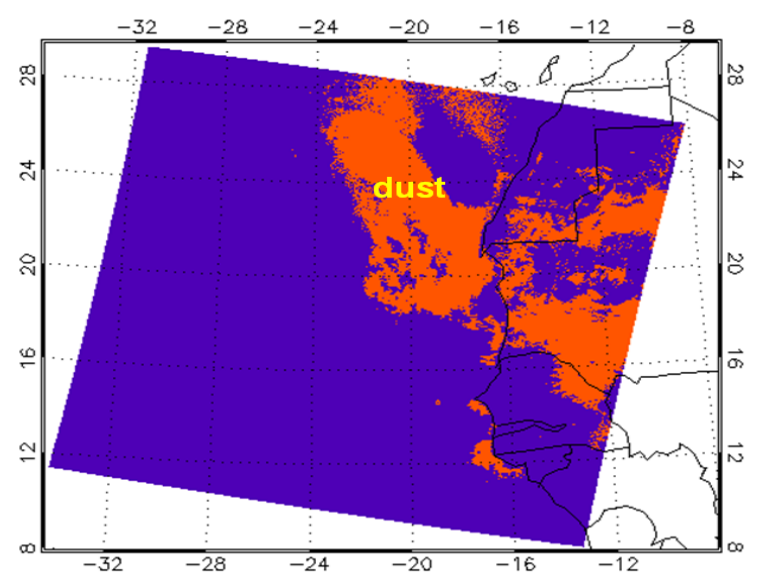


Figure 21. Comparison of RGB image, dust index, AOT, and FMF for the Trans-Atlantic dust case of Figure 17. The gap in AOT and FMF is in sun glint region, where there is no AOT and AFM retrieval available.

Aqua MODIS RGB Image

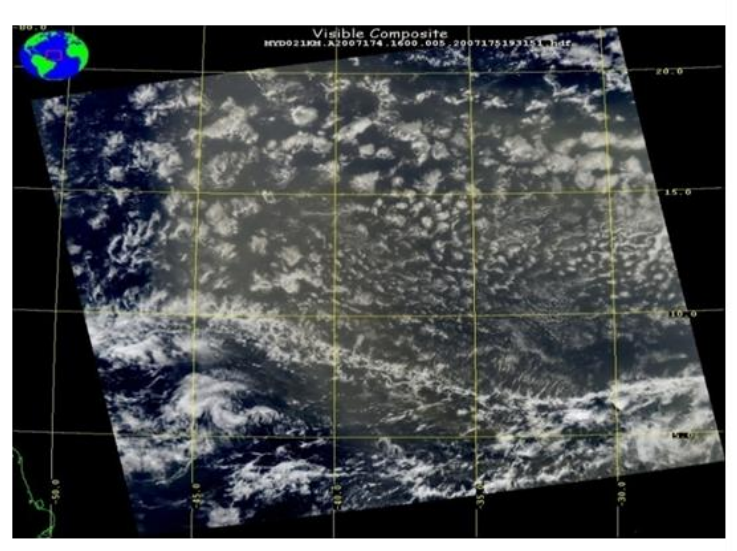

MODIS AOT

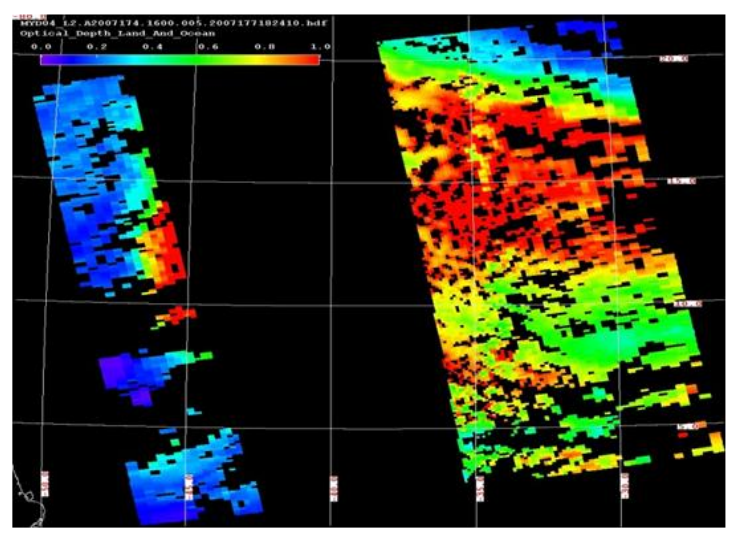

Dust Index

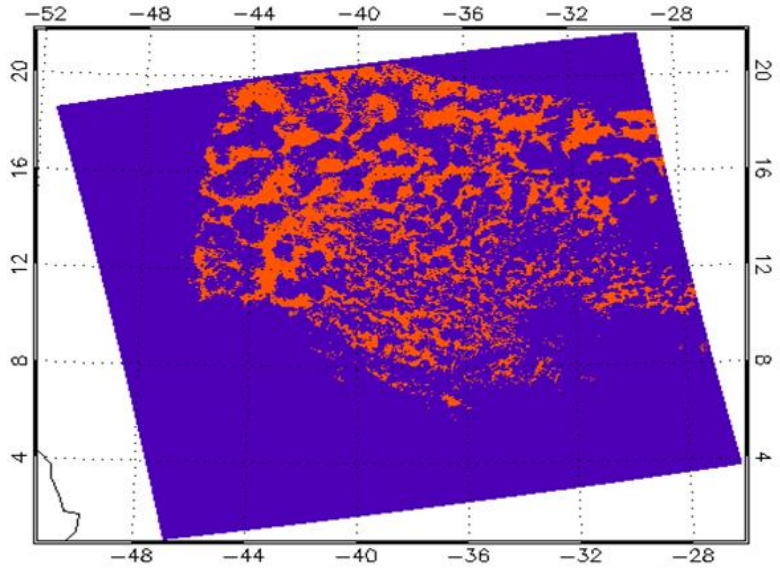

MODIS FMF

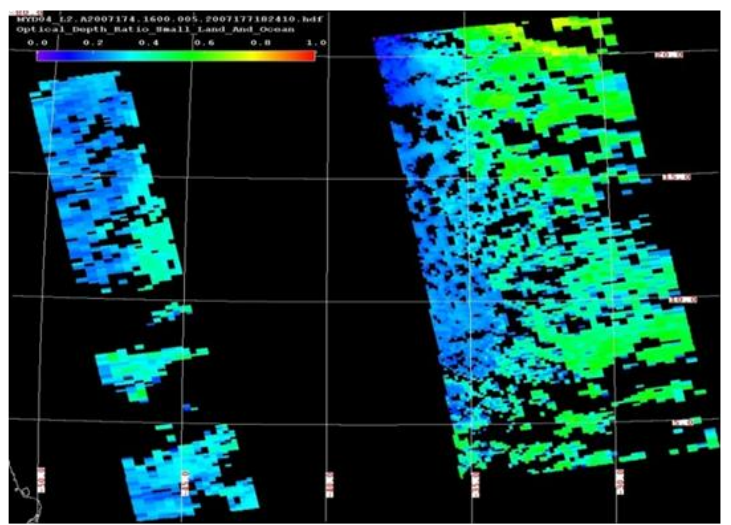

Figure 22. Left: Aqua MODIS AOT on August 19, 2003 at about 19:00 UTC. Right: the results of the smoke detection (pixels flagged as smoky are in red).

MODIS AOT

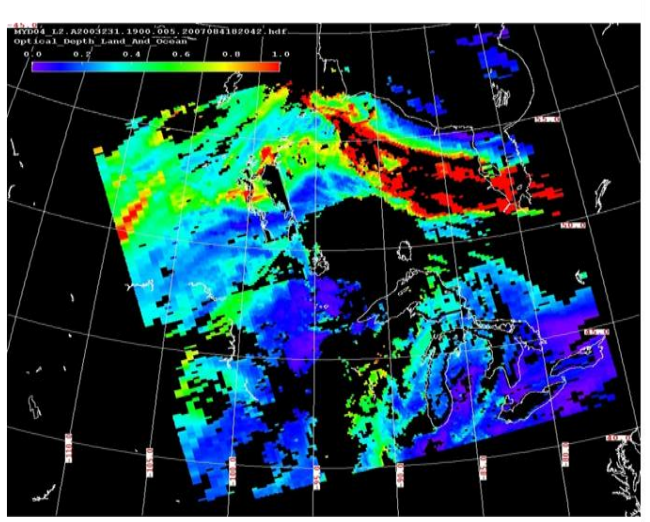

Smoke Index

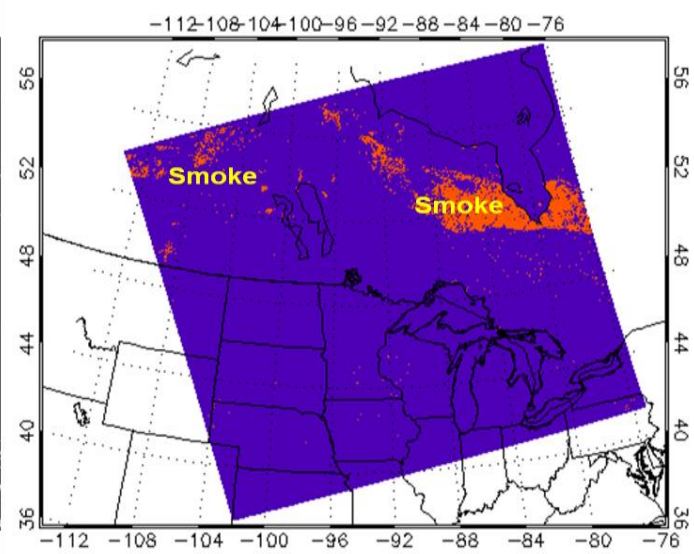




\section{Summary and Conclusions}

A dust and smoke detection algorithm is presented in this paper. The detection product (dust and smoke) is produced for each pixel observed by a satellite multi-channel imager. The detection relies on spectral and spatial threshold tests along with some uniformity texture examinations by using radiances (or reflectances) and brightness temperatures from a multi-channel radiometric imager. The algorithm output is written in HDF format for both smoke and dust flags with values: 0 (no dust/smoke) and 1 (dust/smoke). The detection algorithm is implemented sequentially and designed to run on segments of data instead of pixel by pixel for efficient processing. MODIS observations are used to test the operation and performance of the algorithm.

The algorithm enables detection for all satellite pixels during daytime. It can capture heavy dust and smoke plumes over both land and ocean so that it can be used as a global detection algorithm. Due to the relatively weak aerosol signal and large uncertainties associated with a bright surface, the current algorithm has difficulty capturing thinner or dispersed dust and smoke plumes. It also does not work for the snow/ice surface due to associated strong surface perturbation on the aerosol signal. The algorithm can be applied to any multi-channel imagers (such as current EOS/MODIS and future JPSS/VIIRS and GOES-R/ABI) with proper detection channels used by the algorithm.

The above comparison and evaluation is limited to pre-operation (or pre-launch) phase so that the focus is mainly on indentifying the capability and limitation of the algorithm using some golden validation cases. Since the algorithm is designed for global operational applications, it would be better to provide a conclusive statistical evaluation, based on extensive validation cases accumulated from practical operational runs. The algorithm is designed for the future JPSS/VIIRS and GOES-R/ABI imagers to operationally monitor the outbreak of dust storms and smoke plumes so that conclusive statistic evaluation will be provided once it is up and running. However, we will continually perform comparisons for different scenarios during the evolution of the algorithm in the pre-operation (or pre-launch) phase.

There is room for improvement of the algorithm that can be explored in the future, including (1) alternative detection approach for thinner or dispersed dust and smoke plumes (such as the neural networks approach), (2) refining smoke detection over the ocean to better separate from cloud (especially shallow cloud), (3) extending the smoke detection to semi-arid land surface, (4) exploring smoke and dust detection at night using brightness temperature only, (5) performing additional comparisons by using complementary measurements to the imagers, such as lidar measurement from CALIPSO.

\section{Acknowledgements}

The leader author would like to acknowledge the climate data record (CDR) project at the National Climate Data Center (NCDC) of NOAA for providing the funding support. We also appreciate the suggestions and comments on the manuscript from Ken Knapp and Sharon LeDuc at the NCDC. The encouragement and constructive suggestions from three anonymous reviewers are greatly appreciated. 


\section{References}

1. IPCC. Climate Change 2007: The Physical Science Basis; Working Group I Contribution to the Fourth Assessment Report of the IPCC; Cambridge University Press: New York, NY, USA, 2007; p. 996.

2. Tanré, D.; Legrand, M. On the satellite retrieval of Saharan dust optical thickness over land: Two different approaches. J. Geophys. Res. 1991, 96, 5221-5227.

3. Ackerman, S.A. Using the radiative temperature difference at 3.7 and $11-\mu \mathrm{m}$ to track dust outbreaks. Remote Sens. Environ. 1989, 27, 129-133.

4. Ackerman, S.A. Remote sensing aerosols using satellite infrared observations. J. Geophys. Res. 1997, 102, 17069-17079.

5. Kaufman, Y.J.; Tanré, D.; Remer, L.A.; Vermote, E.F.; Chu, A.; Holben, B.N. Operational remote sensing of tropospheric aerosol over land from EOS moderate resolution imaging spectroradiometer. J. Geophys. Res. 1997, 102, 17051-17067.

6. Verge-Depre, G.; Legrand, M.; Moulin, C.; Alias, A.; Francois, P. Improvement of the detection of desert dust over the Sahel using METEOSAT IR imagery. Ann. Geophys. 2006, 24, 2065-2073.

7. Christopher, S.A.; Kliche, D.V.; Chou, J.; Welch, R.M. First estimates of the radiative forcing of aerosols generated from biomass burning using satellite data. J. Geophys. Res. 1996, 101, 21265-21273.

8. Li, Z.; Khananian, A.; Fraser, R.H.; Cihlar, J. Automatic detection of fire smoke using artifical neural networks and threshold approaches applied to AVHRR imagery. IEEE Trans. Geosci. Remote Sens. 2001, 39, 1859-1870.

9. Prata, A.J. Observations of volcanic ash clouds in the 10-12 $\mu \mathrm{m}$ window using AVHRR/2 data. Int. J. Remote Sens. 1989, 10, 751-761.

10. Barton, I.J.; Prata, A.J.; Watterson, I.G.; Young, S.A. Identification of the Mount Hudson volcanic cloud over SE Australia. Geophys. Res. Lett. 1992, 19, 1211-1214.

11. Legrand, M.; Cautenet, G.; Buriez, J.C. Thermal impact of Saharan dust over land. Part II: Application to satellite IR remote sensing. J. Appl. Meteorol. 1992, 31, 181-193.

12. Legrand, M.; Plana-Fattori, A.; N'Doumé, C. Satellite detection of dust using the IR imagery of Meteosat 1. Infrared difference dust index. J. Geophys. Res. 2001, 106, 18251-18274.

13. Evan, A.T.; Heidinger, A.K.; Pavolonis, M.J. Development of a new over-water Advanced Very High Resolution Radiometer dust detection algorithm. Int. J. Remote Sens. 2006, 27, 3903-3924.

14. Dunion, J.P.; Velden, C.S. The impact of the Saharan air layer on Atlantic tropical cyclone activity. Bull. Amer. Meteorol. Soc. 2004, 85, 353-365.

15. Darmenov, A.; Sokolik, I.N. Identifying the regional thermal-IR radiative signature of mineral dust with MODIS. Geophys. Res. Lett. 2005, 32, doi:10.1029/2005GL023092.

16. Dubovik, O.; Holben, B.; Eck, T.F.; Smirnov, A.; Kaufman, Y.J.; King, M.D.; Tanré, D.; Slutsker, I. Variability of absorption and optical properties of key aerosol types observed in worldwide locations. J. Atmos. Sci. 2002, 59, 590-608.

17. Salomonson, V.V.; Barnes, W.L.; Maymon, P.W.; Montgomery, H.E.; Ostrow, H. MODIS: Advanced facility instrument for studies of the earth as a system. IEEE Trans. Geosci. Remote Sens. 1989, 27, 145-153. 
18. Remer, L.A.; Kaufman, Y.J.; Tanre, D.; Mattoo, S.; Chu, D.A.; Martins, J.V.; Li, R.R.; Ichoku, C.; Levy, R.C.; Kleidman, R.G.; Eck, T.F.; Vermote, E.; Holben, B.N. The MODIS aerosol algorithm, products, and validation. J. Atmos. Sci. 2005, 62, 947-973.

(C) 2010 by the authors; licensee MDPI, Basel, Switzerland. This article is an open access article distributed under the terms and conditions of the Creative Commons Attribution license (http://creativecommons.org/licenses/by/3.0/). 